\title{
C-kit Mutations in Endometrial Cancer: Correlation with Tumor Histologic Type
}

\author{
Taiebeh Kafshdooz ${ }^{1}$, Seyyed Mojtaba Mohaddes Ardabili², Leila Kafshdooz ${ }^{1}$, \\ Ali Dastranj Tabrizi ${ }^{1 *}$, Morteza Ghojazadeh ${ }^{1,2}$, Jalal Gharesouran ${ }^{2}$, Abolfazl \\ Akbarzadeh ${ }^{3 *}$
}

\begin{abstract}
Objective: Endometrial cancer is the fourth most common cancer among women in developed countries. Affected patients may benefit from systemic chemotherapy, alone or in combination with targeted therapies if the disease is clinically diagnosed prior to expansion and metastasis to other organs.The aim of this study was to evaluate the prognostic role of c-kit mutations and comparision with tumor type and grade in human uterine endometrial carcinomas. Materials and Methods: Seventy five patients with endometrial carcinoma and seventy five normal controls were studied for possible mutations in exon 17 of the c-kit gene using single strand conformational polymorphisms and sequencing. Results: c-kit mutation in exon 17 appeared to be significantly different between endometrial carcinoma and normal endometrium. The pattern and frequency of the mutations was also shown to be different between tumors from different stages.
\end{abstract}

Keywords: Endometrial carcinoma - tumor type and grade - c-kit mutation

Asian Pac J Cancer Prev, 16 (17), 7449-7452

\section{Introduction}

Endometrial carcinoma is one of the most common gynecological cancers and is the fourth common cancer in women with 150,000 new cases diagnosed annually worldwide.The incidence rate are up to ten times higher in industrialized countries (Lee et al., 2010; Bekar et al., 2013). Cancers are not only causing high morbidity and distress, but cancers has become a leading cause of death throughout the world (Ezat et al., 2014).

Endometrial carcinoma is the most common invasive malignant neoplasm of the female genital tract, with an estimated 46,470 diagnosed cases and 8,120 deaths in 2011 in the United States (Castellsague et al., 2006).

As in most other cancer diseases, neoplastic progression to EC is very complex, and involves high penetrance genes as well as intricate interactions of multiple low penetrance genes. More than half of all cancer cases and deaths worldwide are potentially preventable. (Karlsson et al., 2009).

Two main types of tumore have been recognized: type I are endometrioid adenocarcinomas, which represent $80 \%$ of endometrial carcinomas, They develop in perior post-menopausal women and are related to estrogen stimulation and as the low grade tumors, type 2 tumors are high-grade non endometrioid carcinomas which invade deeply into the myometrium and follow an aggressive clinical course such as serous carcinomas. (Catasus et al., 2009; Thanapprapasr and Thanapprapasr, 2013).

Approximately $90 \%$ of cases of endometrial carcinoma are sporadic, while the remaining $10 \%$ of cases are hereditary (Kafshdooz et al., 2014). The cause of endometrial cancer remains unclear (Jiang et al., 2014) and numerous genetic alterations have been found in cancer cells (Liu, 2007). It is worth mentioning that, generally, cancers developed after the defect in the DNA repair, inactivation of tumor suppressor genes, and up-regulation of oncogenes (Kafshdooz et al., 2014).

The c-kit proto-oncogene is the cellular homologue of the transmembrane tyrosine kinase receptor (KIT), which is immunologically identified by the CD117 antigenic epitope. It is located on chromosome 4 (4q11-12) in the human genome and codes for a 145 to $160 \mathrm{kDa}$ (Naik and Hasnan, 2008).

It is the receptor for stem cell factor (mast cell growth factor), structurally and functionally closely related to platelet-derived growth factor and macrophage colony stimulating factor (Naik and Hasnan, 2008).

The binding of stem cell factor leads to the dimerization of c-kit proteins, thus initiating a signaling cascade that ultimately induces cell growth. (Sever et al., 2005).

Expression of c-Kit is weak to reasonable in a wide variety of normal, benign, and malignant tissues (Lammie et al., 1994; Tsuura et al., 1994). In a subset of mast cell

${ }^{1}$ Women's Reproductive Health Research Center, ${ }^{2}$ Medical Faculty, ${ }^{3}$ Department of Medical Nanotechnology, Faculty of Advanced Medical Sciences, Tabriz University of Medical Sciences, Tabriz, Iran *For correspondence: dastranjt@gmail.com 
disorders (Boissan et al., 2000). and gastrointestinal stromal cell tumors (Sakurai et al., 1999; Lux et al., 2000). overexpression has been associated to either an activating or dominant- inactivating c-kit mutation.

The aime of this study was to evaluate the prognostic role of c-kit mutation and comparision with tumor type and grade in human uterine endometrial carcinoma. kit mutation is primary molecular changes in endometrial carcinoma.

\section{Materials and Methods}

\section{Patients and methods}

After proposal approved by ethical board of AL-Zahra Educational and Medical Hospital, Tabriz, Iran The tissues used in the present study were formalin-fixed and paraffin-embedded sections (75 endometrial carcinomas) from patients who had been admitted to the Department of Obstetrics and Gynecology from 2011-2013 in the AL-Zahra educational-treatment hospital, Tabriz, IRAN. A pathologist reviewed and confirmed the histological diagnosis of all cases. All cases underwent for grading and staging by FIGO 2009 staging and grading protocol.

\section{DNA Extraction}

DNA was extracted from the tumor paraffin-embedded tissues. Tissues were removed from micro-dissection slides. This slide was used to separate the relevant tissues from the other slides. DNA was extracted by using the QIAamp DNA FFPE Tissue kit (cat. No.56404). Before beginning the procedure, deparaffinization was carried out by the xylen. The extracted genomic DNA was quantified by using nanodrop spectrophotometer.

\section{Primer Design}

Primers for polymerase chain reaction (PCR) amplification and sequencing were designed using the primer 3 program (http://frodo.wi.mit.edu/cgi-bin/primer 3/primer 3-www.cgi). Two primer pairs were used to amplify exon 11 of genomic endometrium.

\section{PCR}

The conditions for the $\mathrm{PCR}$ reaction were denaturation at $95^{\circ} \mathrm{C}$ for $4 \mathrm{~min}$ followed by 35 cycles of denaturation at $95^{\circ} \mathrm{C}$ for $30 \mathrm{~s}$, annealing at $47^{\circ} \mathrm{C}$ for $30 \mathrm{~s}$, and extention at $72^{\circ} \mathrm{C}$ for $30 \mathrm{~s}$, followed by a final extension at $72^{\circ} \mathrm{C}$ for $10 \mathrm{~min}$. The forward primer was 5'-TTG ACA GTT AAA GGC ATT TC-3' and the reverse primer was F:5' -TTACAAGTTAAAATGAATT-3' R:5' AAGTTGAAACTAAAAATCCT-3'

Each $20 \mu 1$ reaction mixture for c-kit amplification contained $100 \mathrm{ng}$ of genomic DNA, $250 \_$M of each deoxynucleotide triphosphate, $1 \mathrm{x}$ _ PCR Buffer II (Perkin-Elmer), 2.5 mM MgCl2, 0-10\% DMSO, 0.5 unit of AmpliTaq Gold (Perkin-Elmer), and $1 \mu \mathrm{M}$ of each primer. PCR amplifications were performed in a PerkinElmer Cetus 9600 thermocycler with denaturation at $94^{\circ} \mathrm{C}$ for $10 \mathrm{~min}$, followed by 35 cycles of $94^{\circ} \mathrm{C}$ for 30 $\mathrm{s}, 44-55^{\circ} \mathrm{C}$ for $30 \mathrm{~s}, 72^{\circ} \mathrm{C}$ for $30 \mathrm{~s}$, and final extension at $72^{\circ} \mathrm{C}$ for $10 \mathrm{~min}$.
Single Strand Conformation Polymorphism (SSCP) and sequencing

SSCP analysis for point mutations was performed under the following conditions: a mixture of $5 \mu \mathrm{l}$ of a 35 -cycle PCR product and $12 \mu \mathrm{l}$ of loading buffer were denatured for $10 \mathrm{~min}$ at $95^{\circ} \mathrm{C}$, cooled rapidly on ice and separated on anon-denaturing $10 \%$ polyacrylamide gel in $1 \times$ Tris borate-EDTA buffer at $4-8^{\circ} \mathrm{C}$ for $16-20 \mathrm{~h}$ at 100 $\mathrm{V}$. Bands were revealed by silver staining.

The PCR products showed a mobility shift by SSCP analysis, which suggested the presence of mutation. The products submitted for direct sequencing.

\section{DNA Sequencing}

Samples that displayed abnormal SSCP patterns were sequenced. Each sample was amplified in a new $25 \mu 1$ PCR reaction and sequenced.

\section{Statistical analysis}

Data of the present underwent for statical analysis using spss software (version16) for identifying of correlation between c-kit mutation in one hand and other type,tumor grade and tumor stage on the other hand.

\section{Results}

\section{Patients and tumors}

Seventy-five endometrial carcinomas were investigated. All of the samples were obtained from Iranian patients. $60 \%$ (45 cases) of the tumors were endometriod and 40\% (30 cases) of the tumors were serous type.

According to FIGO staging system, 63.5\% (33 cases) were stage I, $15.4 \%$ ( 8 cases) were stage II, $15.4 \%$ ( 8 cases) were stage III, and 3 cases were stage IV. Moreover, $25.5 \%$ (14 cases) were grade I, $30.9 \%$ (17 cases) were grade II, and $43.6 \%$ (24 cases) were grade III. The mean age of the patients was 57.6.

\section{PCR-SSCP and sequence analysis results}

We screened exon 17 of the c-kit gene by PCR-SSCP analysis for the presence of mutation in 75 endometrial carcinomas in two groups: low stage and high stage. Examples of the cases that showed mobility shifts by SSCP

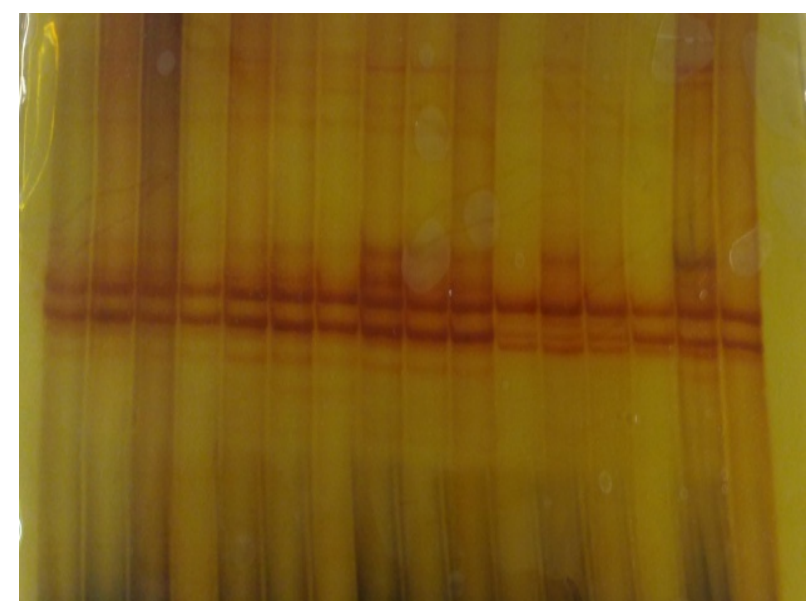

Figure 1. PCR SSCP. PCR-SSCP of exone 17 c-kit gen 


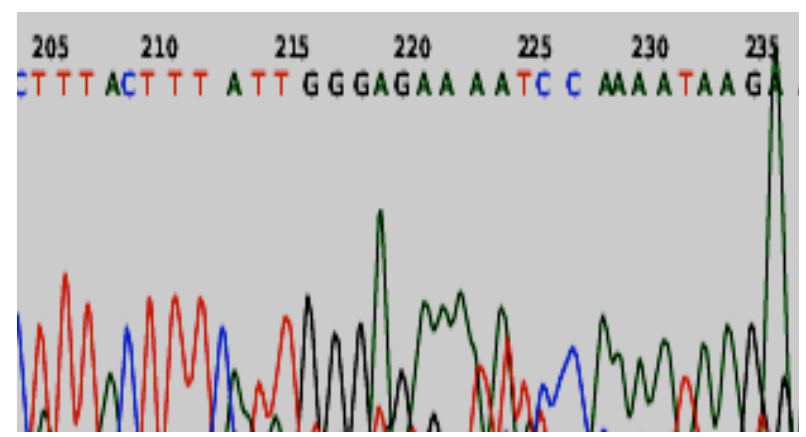

Figure 2. Sequencing. Result of sequencing in sample with point mutation in exon 17 of c-kit gene

analysis are shown in Figure 1. 18.6\% of samples had mutations were subsequently confirmed by sequencing.

In a series of 75 endometrial carcinomas, no mutations were detected in exon 17 in two groups of stages.

\section{Discussion}

It has been reported that in endometrial carcinoma, c-KIT positivity is an adverse prognostic factor(Scobie et al., 2003). Previous studies of endometrial carcinoma comprise a small number of specimens and about immunohistochemical assays. conflicting results of c-KIT staining have been reported in uterine leiomyosarcomas additionally (Miettinen et al., 2000; Abargel et al., 2004).

Similar to our findings in endometrial carcinoma, some level of c-kit mutation has been reported in a high proportion of this neoplasm in other studies, ranging from $44 \%$ to $100 \%$ of the cases (Arber et al., 1998; Alkushi et al., 2003; Abargel et al., 2004). In line with this concept are also other studies of carcinoma that have found similar c-kit mutation in the carcinomatous and epithelial elements (Winter Iii et al., 2003; Leath 3rd et al., 2004). In addition, c-kit has also been made known to be overexpressed in particular types of malignant germ cell tumors, such as seminoma (Meyts and Skakkebkk, 1994; Sakuma et al., 2003).

KIT is well known to be expressed in uterine sarcomas and carcinosarcomas but KIT expression is debatable in endometrial carcinoma. In the current study, we found mutation in $18.66 \%$ cases compared with controls. This suggests it need many number of cases to confirm the role of c-kit mutation in EC.c-kit mutation is a early changes in endometrial carcinoma. Mutations in Exon 17 have been well characterized in the majority of patients with adult onset mastocytosis.

In a wide-ranging study of c-kit expression in numerous tumors, Went et al demonstrated that dysgerminoma (two cases) and gonadoblastoma (one case) both reveal c-kit expression. furthermore, Brenner tumor (33\% staining), cervical adenocarcinoma (33\% staining), and, less frequently, ovarian carcinoma, cervical squamous carcinoma, and vulvar carcinoma all show nominal c-kit expression (Went et al., 2004).

Arber et al(Arber et al., 1998) have recently established by immunohistochemistry that endometrial adenocarcinomas and hyperplastic endometria express CD117.
On the other hand deregulation of the protein kinase activity have a main function in human malignant neoplasms.

The mutations in c-kit different from single base pair substitutions to complex deletions/insertions, but they are regularly in-frame and in many cases have been recognized to cause activation of the KIT kinase autonomous of its natural ligand, stem cell factor(Rubin et al., 2001).

Endometrial cancer is a heterogeneous disease with complex genetic and environmental influences. It has been proposed that environmental risk factors such as obesity and overexposure to endogenous or exogenous hormones may be concerned in the pathogenesis of endometrial carcinoma(Niwa et al., 2005).

Slomovitz et al. In 2004 reported no KIT expression in endometrial carcinoma but Scobie et al. In 2003 showed frequent cytoplasmic expression of KIT in endometrial carcinoma.

Howevere due to contentious and challenging aspects of this background,other studies with describing detail molecular findings in different types of endometrial carcinoma is necessary.

In conclusion, it can be said that endometrial cancer is characterized by numerous genetic alterations, including those in p53, K-ras, PTEN and $\beta$-catenin. The study demonstrated that mutation of c-kit increase the risk of endometrial cancer, Thus, further studies with larger samples need to be carried out in order to clarify new mutation site and the role of this mutation in the oncogenesis of endometrial cancer among Iranian women.

\section{Acknowledgements}

We would like to thank authorities of Tabriz University of Medical Sciences for the scientific and ethical approval and financial support of this research. This study has been done as a msc thesis of taiebeh kafshdooz in Women's Reproductive Health Research Center, Tabriz University of Medical Sciences.

\section{References}

Abargel A, Avinoach I, Kravtsov V, et al (2004). Expression of p27 and p53: comparative analysis of uterine carcinosarcoma and endometrial carcinoma. Int J Gynecological Cancer, 14, 354-9.

Alkushi A, Irving J, Hsu F, et al (2003). Immunoprofile of cervical and endometrial adenocarcinomas using a tissue microarray. Virchows Archiv, 442, 271-7.

Arber DA, Tamayo R, Weiss LM (1998). Paraffin section detection of the $\mathrm{c}-<\mathrm{i}>\mathrm{kit}<\mathrm{i}>$ gene product $(\mathrm{CD} 117)$ in human tissues: Value in the diagnosis of mast cell disorders. Human pathol, 29, 498-504.

Boissan M, Feger F, Guillosson JJ, et al (2000). c-Kit and c-kit mutations in mastocytosis and other hematological diseases. J Leukocyte Biol, 67, 135-48.

Castellsague X, Diaz M, De Sanjose S, et al (2006). Worldwide human papillomavirus etiology of cervical adenocarcinoma and its cofactors: implications for screening and prevention. J National Cancer Inst, 98, 303-15.

Catasus L, Gallardo A, Cuatrecasas M, et al (2009). Concomitant PI3K-AKT and p53 alterations in endometrial carcinomas 


\section{Taiebeh Kafshdooz et al}

are associated with poor prognosis. Modern Pathol, 22, $522-9$.

Jiang X-F, Tang Q-L, Zou Y, et al (2014). Does HBV infection increase risk of endometrial carcinoma? Asian Pac J Cancer Prev, 15, 713-6.

Kafshdooz T, Tabrizi AD, Ardabili SMM, et al (2014). Polymorphism of p53 Gene Codon 72 in Endometrial Cancer: Correlation with Tumor Grade and Histological Type. Asian Pac J Cancer Prev, 15, 9603-6.

Karlsson S, Olsson B, Klinga-Levan K (2009). Gene expression profiling predicts a three-gene expression signature of endometrial adenocarcinoma in a rat model. Cancer Cell Int $, 9,12$.

Lammie A, Drobnjak M, Gerald W, et al (1994). Expression of $\mathrm{c}-\mathrm{kit}$ and kit ligand proteins in normal human tissues. $J$ of Histochem Cytochem, 42, 1417-25.

Leath $3^{\text {rd }}$ CA, Straughn Jr JM, Conner MG, et al (2004). Immunohistochemical evaluation of the c-kit protooncogene in sarcomas of the uterus: a case series. $J$ Reproduct Med, 49, 71-5.

Lee E-J, Kim T-J, Kim DS, et al (2010). p53 alteration independently predicts poor outcomes in patients with endometrial cancer: a clinicopathologic study of 131 cases and literature review. Gynecol oncol, 116, 533-8.

Liu F-S (2007). Molecular carcinogenesis of endometrial cancer. Taiwanese J Obstet Gynecol, 46, 26-32.

Lux ML, Rubin BP, Biase TL, et al (2000). KIT extracellular and kinase domain mutations in gastrointestinal stromal tumors. Am J Pathol, 156, 791-5.

Meyts ERD, Skakkebkk NE (1994). Expression of the c-kit protein product in carcinoma-in-situ and invasive testicular germ cell tumours. Int $J$ Androl, 17, 85-92.

Miettinen M, Sobin LH, Sarlomo-Rikala M (2000). Immunohistochemical spectrum of GISTs at different sites and their differential diagnosis with a reference to CD117 (KIT). Modern Pathol, 13, 1134-42.

Naik VR, Hasnan J (2008). C-kit proto-oncogene expression in uterine leiomyosarcomas: case series. Int Med J, 7, 51-4.

Niwa Y, Hirose K, Matsuo K, et al (2005). Association of< i $>$ p $73</$ i $>$ G4C14-to-A4T14 polymorphism at exon 2 and $<\mathrm{i}>\mathrm{p} 53</ \mathrm{i}>\operatorname{Arg} 72$ Pro polymorphism with the risk of endometrial cancer in Japanese subjects. Cancer letters, 219, 183-90.

Rubin BP, Singer S, Tsao C, et al (2001). KIT activation is a ubiquitous feature of gastrointestinal stromal tumors. Cancer Res, 61, 8118-21.

Sakuma Y, Sakurai S, Oguni S, et al (2003). Alterations of the c-kit gene in testicular germ cell tumors. Cancer science, 94, 486-91.

Sakurai S, Fukasawa T, Chong JM, et al (1999). C-kit gene abnormalities in gastrointestinal stromal tumors (tumors of interstitial cells of cajal). Cancer Science, 90, 1321-8.

Scobie JV, Acs G, Bandera CA, et al (2003). C-kit immunoreactivity in endometrial adenocarcinomas and its clinicopathologic significance. Int J Gynecol Pathol, 22, 149-55.

Sever M, Jones TD, Roth LM, et al (2005). Expression of CD117 (c-kit) receptor in dysgerminoma of the ovary: diagnostic and therapeutic implications. Modern Pathol, 18, 1411-6.

Thanapprapasr D, Thanapprapasr K (2013). Molecular therapy as a future strategy in endometrial cancer. Asian Pac J Prev, 14, 3419-23.

Tsuura Y, Hiraki H, Watanabe K, et al (1994). Preferential localization of c-kit product in tissue mast cells, basal cells of skin, epithelial cells of breast, small cell lung carcinoma and seminoma/dysgerminoma in human: immunohistochemical study on formalin-fixed, paraffin-embedded tissues.
Virchows Archiv, 424, 135-41.

Went PT, Dirnhofer S, Bundi M, et al (2004). Prevalence of KIT expression in human tumors. J Clin Oncol, 22, 4514-22.

Winter Iii WE, Seidman JD, Krivak TC, et al (2003). Clinicopathological analysis of $<\mathrm{i}>\mathrm{c}-\mathrm{kit}<\mathrm{i}>$ expression in carcinosarcomas and leiomyosarcomas of the uterine corpus. Gynecol Oncol, 91, 3-8. 